\title{
Isolation Scribing on Hybrid Films for CIGS-Based Solar Cell Using Various Nanosecond Pulsed Laser Wavelengths
}

\author{
Ming-Fei Chen", Wen-Tse Hsiao ${ }^{* *}$, Ming-Cheng Wang ${ }^{*}$ and Ying-Fang Chen ${ }^{*}$ \\ * Department of Mechatronics Engineering, National Changhua University of Education, Taiwan, \\ No.1, Jin-De Road, Changhua City, 50007, Taiwan \\ ** Instrument Technology Research Center, National Applied Research Laboratories, Taiwan, No.20, \\ R\&D Rd. VI, Hsinchu Science Park, Hsinchu, 30076, Taiwan \\ E-mail: wentse@narlabs.org.tw
}

\begin{abstract}
Taking into account the absorption spectra of the hybrid-film (i.e., molybdenum (P1), copper indium gallium selenide (CIGS)/CdS/i-ZnO (P2), and AZO/CIGS/CdS/i-ZnO (P3)) layers of CIGSbased solar cells, we investigate the hybrid films of CIGS-based solar cells. P1, P2, and P3 isolated layer scribing is performed using infrared $(1064 \mathrm{~nm})$ and ultraviolet $(355 \mathrm{~nm})$ laser systems. The effects of different lasers on the P1, P2, and P3 isolated layers are discussed in terms of the scribing width and depth, bottom residuals, and edge debris. Subsequently, through energy-dispersive spectrometry and three-dimensional confocal laser scanning microscopy, we obtain the optimal laser process parameters. The experimental results obtained using nanosecond lasers are similar to those obtained using femto- and picosecond lasers in the literature.
\end{abstract}

DOI: $10.2961 / \mathrm{jlmn} .2016 .02 .0015$

Keywords: hybrid films, CIGS-based solar cell, isolation, scribing, infrared and ultraviolet laser

\section{Introduction}

Copper indium gallium selenide (CIGS) thin-film solar cells have the following advantages: (a) high photoelectric conversion efficiency, (b) high stability, (c) high efficiency for large-area components, (d) long service life, (e) low cost, and (f) wide application. Consequently, CIGS solar cells have attracted considerable attention in both academia and the industry. CIGS solar cells combined with flexible substrates may have wider applications, creating numerous business opportunities. Because laser scribing processing is excellent at maintaining narrow and straight cutting lines, it can improve the efficiency and quality of solar cell manufacturing. Lasers are expected to gradually supersede the traditional mechanical scribing process. Some studies have discussed the effect parameters by using different lasers for photovoltaic P1-to-P3-layer scribing.

Compaan et al. [1] used lasers of different wavelengths, such as Nd:YAG (355 nm, $1064 \mathrm{~nm}), \mathrm{XeCl}(308 \mathrm{~nm})$, and $\mathrm{KrF}(248 \mathrm{~nm})$, to cut various thin-film silicon solar cells, including CdTe, CIGS, $\mathrm{ZnO}$, and $\mathrm{Al}$, and analyzed the interrelationship of laser systems comprised of different materials. Westin et al. [2] used a 532-nm Nd:YVO laser to remove the P2 layer of a CIGS thin-film solar cell and reported its feasibility and the related optimal processing parameters. Račiukaitis et al. [3] scribed the ITO layer of CIGS thin-film solar cells by using an ultraviolet laser and performed elemental analysis through scanning electron microscopy (SEM) and energy-dispersive spectroscopy (EDS). Rekow et al. [4] used a fiber laser with a programmable control pulse frequency to scribe P1, P2, and P3 CIGS solar cells, effectively removing the molybdenum layer. The melting condition of novel laser material processing can be explained using the physical phenomenon discussed in their study. Heise et al. [5], Gecys et al. [6], and Westin et al. [7] conducted P3-layer laser scribing to remove only AZO films and both AZO and CIGS films and reported that removing only AZO films yielded relatively more favorable results because AZO removal damaged the molybdenum layer and affected the electrical properties of the film. Turan et al. [8] reported the front-contact separation processes of a transparent conductive oxide material, such as aluminum-doped zinc oxide ( $\mathrm{ZnO}: \mathrm{Al})$ and fluorinedoped tin dioxide $\left(\mathrm{SnO}_{2}: \mathrm{F}\right)$, on a glass substrate for a thinfilm solar module; these processes entail nanosecond laser ablation at 355, 532, and $1064 \mathrm{~nm}$. In addition, they discussed the electrical and surface morphological characterizations achieved through laser scribing. $\mathrm{Ku}$ et al. [9] discussed the properties of P3-layer isolation in an a-Si:H/ $\mu \mathrm{c}-$ $\mathrm{Si}$ solar module that entails nanosecond-pulse ultraviolet (UV) lasing from the film side. Matulionis et al. [10] used six types of laser sources for scribing polycrystalline thinfilm PV materials such as $\mathrm{ZnO}, \mathrm{SnO}_{2}, \mathrm{CdTe}$, CIGS, Mo, and Si. Dunsky and Colville [11] used a solid-state laser to scribe the P1, P2, and P3 layers for photovoltaic solar cell applications. The experimental results revealed that transparent conductive oxide thin-film scribing requires a laser wavelength and power of $1064 \mathrm{~nm}$ and 5-8 W, respectively, whereas a-Si thin-film scribing requires a 532-nm green laser source and a laser power of 200-500 mW. Moreover, metal thin-film scribing requires a 532-nm-wavelength laser. 
Therefore, in this study, we investigated the P1, P2, and P3 isolated layers of CIGS-based thin-film solar cells. Scribing isolation was performed using 1064- and 355-nm nanosecond pulsed lasers. The results showed that the width, depth, bottom residual, and edge debris of the scribed layers (i.e., P1: molybdenum (Mo) thin film, P2: CIGS/Cds/i-ZnO thin film, and P3: CIGS/Cds/i-ZnO/AZO thin film) depend on the laser power and pulse repetition frequency. Moreover, isolation scribing film characteristics were systematically analyzed using a field-emission (FE) SEM, EDS, and 3D confocal laser scanning microscopy.

\section{Experimental details}

\subsection{Sample prepared}

The Mo, CIGS, i-ZnO, and $\mathrm{ZnO}: \mathrm{Al}$ (AZO) thin-film layers were deposited on a soda-lime glass substrate through the sputter method. The CdS layer was deposited using the chemical bath deposition method. Figure 1 presents the SEM photographs of the experimental materials coated in the following order: Mo electrode, CIGS (absorption layer), CdS (buffer layer), i-ZnO (light transmission layer), and $\mathrm{ZnO}: \mathrm{Al}$ ( $\mathrm{AZO}$; front electrode). The thicknesses of the deposited Mo, CIGS, CdS, i-ZnO, and thin-film layers were approximately $600-700,600-700,100,100$, and 600-700 nm, respectively. The surface morphological views of the as-deposited Mo, CIGS, CdS, i- $\mathrm{ZnO}$, and $\mathrm{ZnO}: \mathrm{Al}$ films on the glass substrates were recorded through FE-SEM (Hitachi S-4300). In addition, optical absorption was measured through ultraviolet (UV)-visible/near infrared (NIR) spectrophotometry (Jasco V-670).

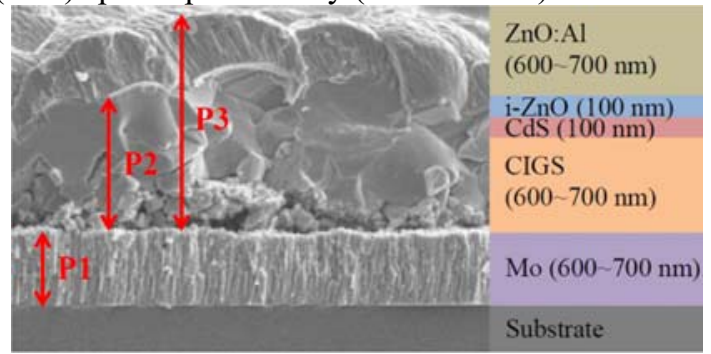

Fig. 1 SEM photographs of CIGS-based thin film solar cells.

Figure 2 illustrates the P1, P2, and P3 laser isolation scribing process for a CIGS-based thin-film solar module. Figure 3 shows the absorption spectra of these P1 (red dashed line), P2 (blue dot-dashed line), and P3 (black solid line) layers. Table 1 summarizes the properties of each layer (P1-P3) of the as-deposited films on the glass substrates.

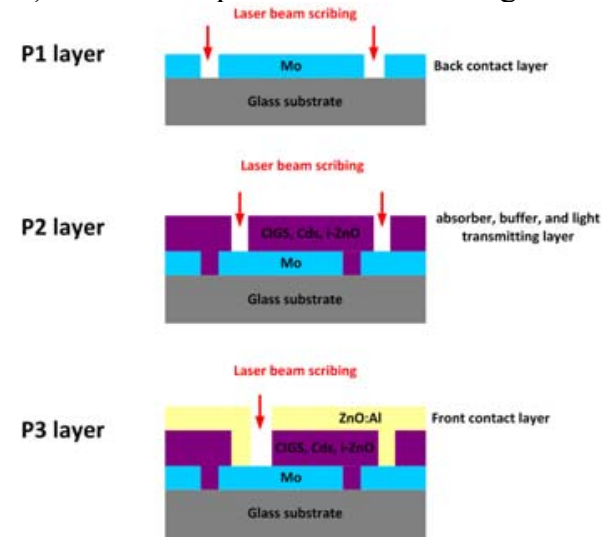

Fig. 2 Schematic diagram of the CIGS-based PV module laser

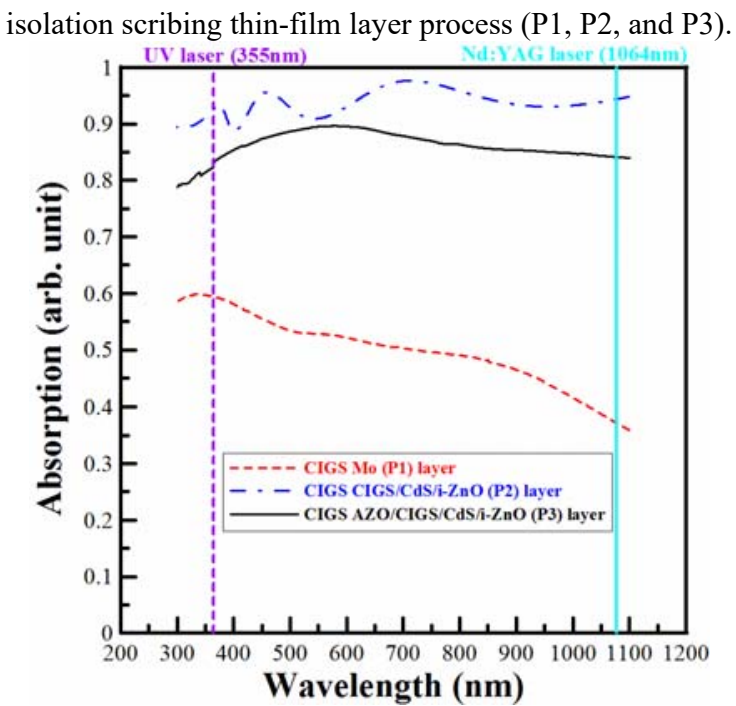

Fig. 3 Optical absorption of the as-deposited CIGS-based solar cell P1, P2, and P3 layer.

Table 1 CIGS-based solar cells P1 to P3 layer properties of asdeposited on glass substrates.

\begin{tabular}{|c|c|c|c|}
\hline Layer & $\begin{array}{l}\text { Thin film } \\
\text { materials }\end{array}$ & $\begin{array}{c}\text { Thickness } \\
\text { (nm) }\end{array}$ & $\begin{array}{c}\text { Absorption (arb. } \\
\text { unit) (@1064nm } \\
\text { / 355nm) }\end{array}$ \\
\hline $\mathrm{P} 1$ & Mo & 700 & $0.38 / 0.6$ \\
\hline $\mathrm{P} 2$ & CIGS / CdS / i-ZnO & 900 & $0.94 / 0.92$ \\
\hline P3 & $\begin{array}{c}\mathrm{CIGS} / \mathrm{CdS} / \mathrm{i}-\mathrm{ZnO} \\
\text { / Mo }\end{array}$ & 1600 & $0.84 / 0.82$ \\
\hline
\end{tabular}

\subsection{Experimental setup of laser isolation scribing sys- tems}

Two types of laser scribing systems were used in our experiments: a 1064-nm IR laser system and a 355-nm UV laser system. Each laser system comprised a laser source, a beam delivery system, a focusing lens, and a PC-based controller. The IR laser system used a fundamental generator Nd: $\mathrm{YVO}_{4}$ laser crystal of wavelength $1064 \mathrm{~nm}$ (AWAVE 1064-20W-100K, Advanced Optowave Corp.). The pulse repetition frequency was adjusted between 1 and $100 \mathrm{kHz}$, and the maximum average output power of the laser exceeded $20 \mathrm{~W}$. The beam delivery system included a mirror with a reflectivity value of $>99.5 \%$, a $5 \times$ magnification beam expander, a high-speed galvanometric scanner, and an F-theta scan lens. Further, the UV laser system used a third-harmonic generator $\mathrm{Nd}: \mathrm{YVO}_{4}$ laser crystal of wavelength $355 \mathrm{~nm}$ (AWAVE 355-4W-30K, Advanced Optowave Corp.). The maximum pulse repetition frequency and the average output power were $100 \mathrm{kHz}$ and $4 \mathrm{~W}$, respectively. The complete specifications of the experimental system are presented in Tables 2(a) and (b).

Several CIGS thin-film solar cells similar to those shown in Fig. 2 were manufactured in this study. Laser powers and frequencies for the fundamental generator $\mathrm{Nd}: \mathrm{YVO}_{4}$ laser and the UV laser were modified to remove the P1, P2, and P3 layers from the fabricated solar cells. Through EDS and 3D confocal microscopy, we obtained the optimized laser process parameters. The 2D and 3D morphology images, line width, and line depth were evalu- 
ated using $3 \mathrm{D}$ confocal microscopy. The line-scribed bottom residual elements were analyzed through EDS.

Table 2 (a) Specification of laser processing system- fundamental $\mathrm{Nd}: \mathrm{YVO}_{4}$ laser system

\begin{tabular}{lc}
\hline \multicolumn{1}{c}{ Item } & Values \\
\hline Wavelength $(\mathrm{nm})$ & 1064 \\
\hline Average power $($ Watt $)$ & $>20$ \\
\hline Pulse width $(\mathrm{ns})$ & $\sim 70$ \\
\hline Spatial mode & TEM $_{00}$ \\
\hline Beam quality $\left(\mathrm{M}^{2}\right)$ & $<1.3$ \\
\hline Maximum pulse repetition frequence $(\mathrm{kHz})$ & $\sim 100$ \\
\hline Output Beam diameter, $\pm 10 \%(\mathrm{~mm})$ & 0.8 \\
\hline Focused beam diameter $(\mu \mathrm{m})$ & 50 \\
\hline
\end{tabular}

Table 2 (b) Specification of laser processing system- UV laser system

\begin{tabular}{lc}
\hline \multicolumn{1}{c}{ Item } & Values \\
\hline Wavelength $(\mathrm{nm})$ & 355 \\
\hline Average power $($ Watt $)$ & $>3$ \\
\hline Pulse width $(\mathrm{ns})$ & $\sim 30$ \\
\hline Spatial mode & TEM $_{00}$ \\
\hline Beam quality $\left(\mathrm{M}^{2}\right)$ & $<1.3$ \\
\hline Maximum pulse repetition frequence $(\mathrm{kHz})$ & $\sim 100$ \\
\hline Output Beam diameter, $\pm 10 \%(\mathrm{~mm})$ & 0.4 \\
\hline Focused beam diameter $(\mu \mathrm{m})$ & 30 \\
\hline
\end{tabular}

To obtain favorable isolation scribing results (i.e., to prevent microcrack development and substrate damage), the operating parameters, such as laser power and pulse repetition frequency, were set as listed in Table 3.

\section{Experimental results}

\subsection{Fundamental $\mathrm{Nd}: \mathrm{YVO}_{4}$ laser isolation scribing of molybdenum (P1) thin-film layer}

\subsubsection{Effect of different laser powers}

Figure 4 shows the morphological images of the molybdenum (P1) thin-film layer scribed using the fundamental generator $\mathrm{Nd}: \mathrm{YVO}_{4}$ laser at different laser powers of (a) $0.5 \mathrm{~W}$, (b) $0.22 \mathrm{~W}$, and (c) $0.43 \mathrm{~W}$. According to the $3 \mathrm{D}$ confocal microscopy images, the measured scribed line width and depth were (a) $\mathrm{w}=27.8 \mu \mathrm{m}, \mathrm{d}=1.04 \mu \mathrm{m}$; (b) $\mathrm{w}$ $=46.9 \mu \mathrm{m}, \mathrm{d}=0.81 \mu \mathrm{m}$; and (c) $\mathrm{w}=50.8 \mu \mathrm{m}, \mathrm{d}=0.93 \mu \mathrm{m}$, respectively. Figure 4(a) shows the slag phenomenon and heat-affected zone around the scribed line region produced at $0.5 \mathrm{~W}$. At $0.22 \mathrm{~W}$, the molybdenum thin film at the bottom sidewall could not be effectively removed, as shown in Figs. 4(b) and (c). However, molybdenum thin films could be effectively ablated at $0.43 \mathrm{~W}$. The scribing edge did not exhibit the slag phenomenon at this power.
Table 3 Isolation laser scribing parameters for CIGS-based thinfilm solar cells P1, P2, and P3 layers.

Isolation layer Used Laser power Pulse repetition

laser $\quad(\mathrm{W}) \quad$ frequency $(\mathrm{kHz})$

\begin{tabular}{|c|c|c|c|}
\hline $\begin{array}{c}\text { P1 } \\
\text { (Mo) }\end{array}$ & $\begin{array}{l}\mathrm{Nd}: \mathrm{YVO}_{4} \\
(1064 \mathrm{~nm})\end{array}$ & $\begin{array}{c}0.22 \\
0.43 \\
0.5\end{array}$ & $\begin{array}{c}60 \\
70 \\
80 \\
90 \\
100\end{array}$ \\
\hline $\begin{array}{c}\mathrm{P} 2 \\
(\mathrm{CIGS} / \mathrm{CdS} / \mathrm{i}-\mathrm{ZnO})\end{array}$ & $\begin{array}{c}\text { UV } \\
(355 \mathrm{~nm})\end{array}$ & $\begin{array}{l}0.3 \\
0.4 \\
0.5 \\
0.6 \\
0.7\end{array}$ & $\begin{array}{l}10 \\
20 \\
30\end{array}$ \\
\hline $\begin{array}{c}\mathrm{P} 3 \\
(\mathrm{AZO} / \mathrm{CIGS} / \mathrm{CdS} / \mathrm{i}- \\
\mathrm{ZnO})\end{array}$ & $\begin{array}{c}\mathrm{UV} \\
(355 \mathrm{~nm})\end{array}$ & $\begin{array}{l}0.4 \\
0.5 \\
0.6 \\
0.7 \\
0.8\end{array}$ & $\begin{array}{c}50 \\
60 \\
70 \\
80 \\
90 \\
100\end{array}$ \\
\hline
\end{tabular}
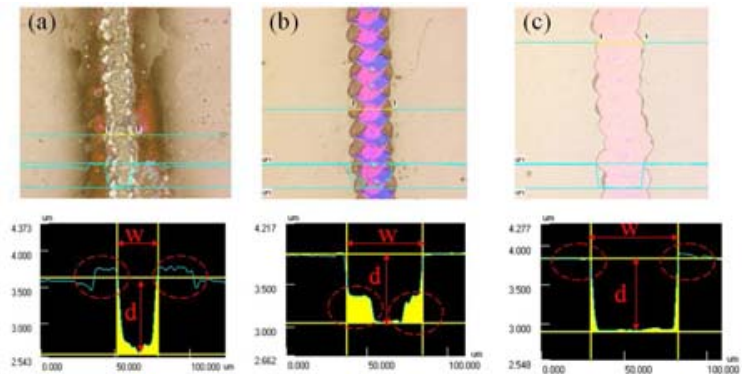

of the $\mathrm{Nd}: \mathrm{YVO}_{4}$ laser

Fig. 4 3D confocal microscope images of the $\mathrm{Nd}: \mathrm{YVO}_{4}$ laser scribing molybdenum (P1) thin film layer at different laser powers. (a) laser power of $0.5 \mathrm{~W}$, (b) laser power of $0.22 \mathrm{~W}$, and (c) laser power of $0.43 \mathrm{~W}$

\subsubsection{Effect of different laser powers}

To investigate the effect of the scribing line width of the operating frequencies, laser power was fixed at $0.2 \mathrm{~W}$. Figure 5 shows the optical microscopy images of the fundamental generator $\mathrm{Nd}: \mathrm{YVO}_{4} \mathrm{P} 1$ layer laser scribed at different laser frequencies: (a) $100 \mathrm{kHz}$, (b) $90 \mathrm{kHz}$, (c) 80 $\mathrm{kHz}$, (d) $70 \mathrm{kHz}$, and (e) $60 \mathrm{kHz}$. The experimental results indicated that the operation frequency does not influence the scribed line width.

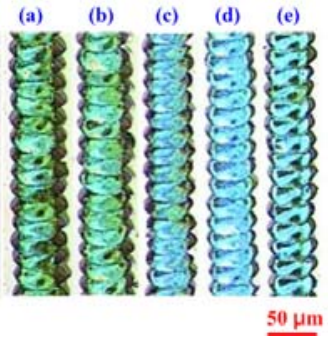

Fig. 5 Optical microscope images of the $\overline{\mathrm{Nd}}: \mathrm{YVO}_{4}$ laser scribing molybdenum (P1) thin film layer at different laser frequencies. (a) $100 \mathrm{kHz}$, (b) $90 \mathrm{kHz}$, (c) $80 \mathrm{kHz}$, (d) $70 \mathrm{kHz}$, and (e) $60 \mathrm{kHz}$. 
3.1.3 Optimal isolation scribing parameter results for Nd:YVO4 laser scribing of molybdenum (P1) thin-film layer

Figure 6 shows the confocal microscope images of fundamental generator $\mathrm{Nd}: \mathrm{YVO}_{4}$ laser scribing molybdenum (P1) thin films at the optimal laser power and laser frequency of $0.3 \mathrm{~W}$ and $80 \mathrm{kHz}$, respectively. The 3D confocal microscope image shows that the laser-scribed edge presents no residual slag phenomenon. The measured line width and depth were 36.8 and $0.96 \mu \mathrm{m}$, respectively. Figure 7 shows the residual element analysis of molybdenum thin films scribed using through EDS. Compared with the as-deposited molybdenum thin films (Figs. 7(c) and (d)), after isolation scribing, the line presents no molybdenum residual in the scribing region (Figs. 7(a) and (b)). (a)
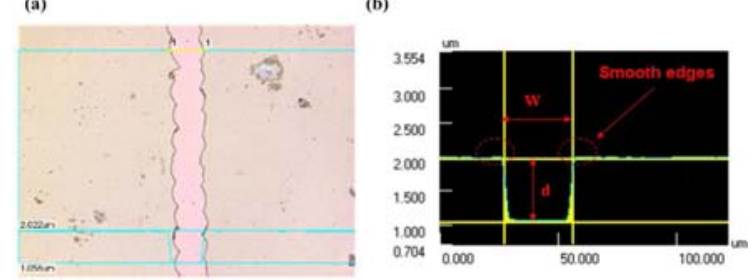

Fig. 6 Optimal results of 2D and 3D confocal microscope image of the $\mathrm{Nd}: \mathrm{YVO}_{4}$ laser scribing molybdenum (P1) thin film.

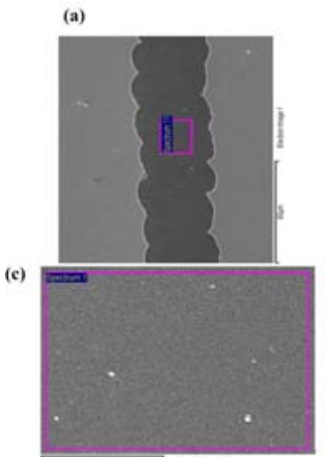

(b)

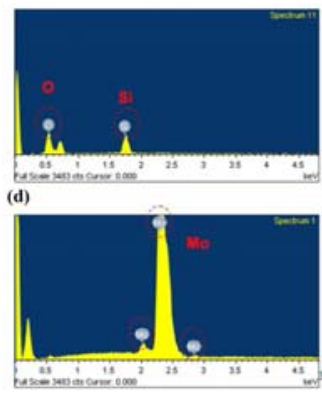

Fig. 6 EDS analysis of non-scribed and scribed regions of molybdenum (P1) thin film.

\subsection{UV laser isolation scribing of $\mathrm{CIGS} / \mathrm{CdS} / \mathrm{i}-\mathrm{ZnO}$ (P2) thin-film layer}

\subsubsection{Effect of different laser powers}

Figure 8 presents the 2D and 3D morphological images of the CIGS/CdS/i-ZnO (P2) thin-film layer scribed using the UV laser at (a) $0.3 \mathrm{~W}$, (b) $0.4 \mathrm{~W}$, (c) $0.5 \mathrm{~W}$, (d) $0.6 \mathrm{~W}$, and (e) $0.7 \mathrm{~W}$. A low laser energy residue is observed at the bottom of the scribed line. When the laser energy was increased to $0.6 \mathrm{~W}$, no residual remained at the bottom of the scribed line. When the laser power was set at $0.7 \mathrm{~W}$, the P2-layer bottom was damaged. Figure 9 shows that the scribed line width and depth increase as the laser power increased from 65.6 to $69.4 \mu \mathrm{m}$ and 0.87 to $1.19 \mu \mathrm{m}$, respectively.

\subsubsection{Effect of different operation frequencies}

The scribing speed, laser power, and positive defocus parameters were fixed, and only the laser frequency was adjusted to obtain the optimized operating frequency. The effects of the laser operating frequency on the scribing depth performance are discussed herein. The laser operating frequency was changed from 10 to $100 \mathrm{kHz}$ in intervals of $10 \mathrm{kHz}$. Figure 10 shows the optical microscopy images of $\mathrm{CIGS} / \mathrm{CdS} / \mathrm{i}-\mathrm{ZnO}$ (P2) thin-film layer laser scribing. When the laser operating frequencies were set at 70 and 80 $\mathrm{kHz}$, a clear scribed track bottom could be obtained. When the laser frequencies were lower than $60 \mathrm{kHz}$, some areas of the substrates were damaged. Heat sintering damage was generated in the track scribed at $10-30 \mathrm{kHz}$.
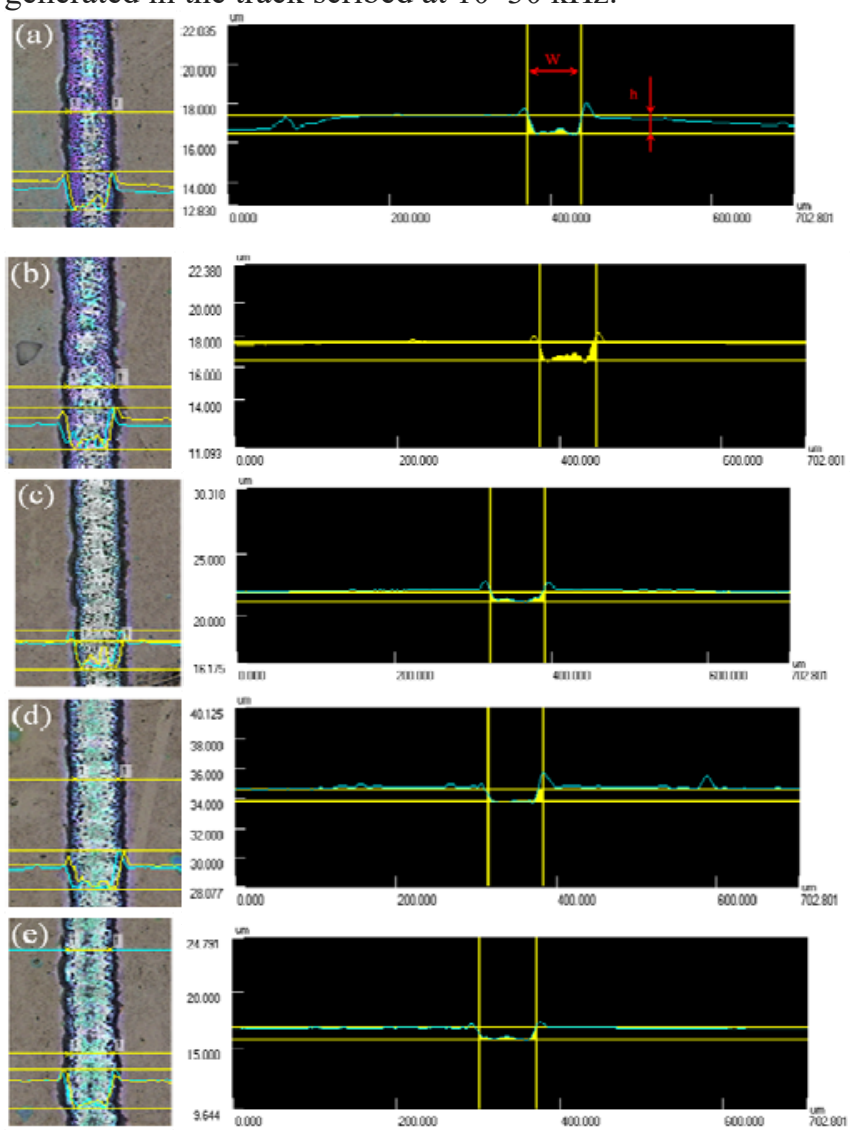

Fig. 8 3D confocal microscope images of the UV laser scribing $\mathrm{CIGS} / \mathrm{CdS} / \mathrm{i}-\mathrm{ZnO}$ (P2) thin-film layer at different laser powers. (a) $0.3 \mathrm{~W}$, (b) $0.4 \mathrm{~W}$, (c) $0.5 \mathrm{~W}$, (d) $0.6 \mathrm{~W}$, and (e) $0.7 \mathrm{~W}$.

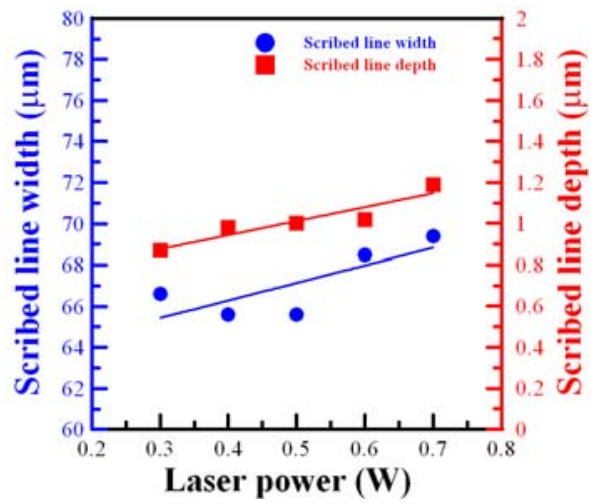

Fig. 9 Line depth and width of the UV laser scribing CIGS/CdS/i$\mathrm{ZnO}(\mathrm{P} 2)$ thin-film layer at different laser powers. 


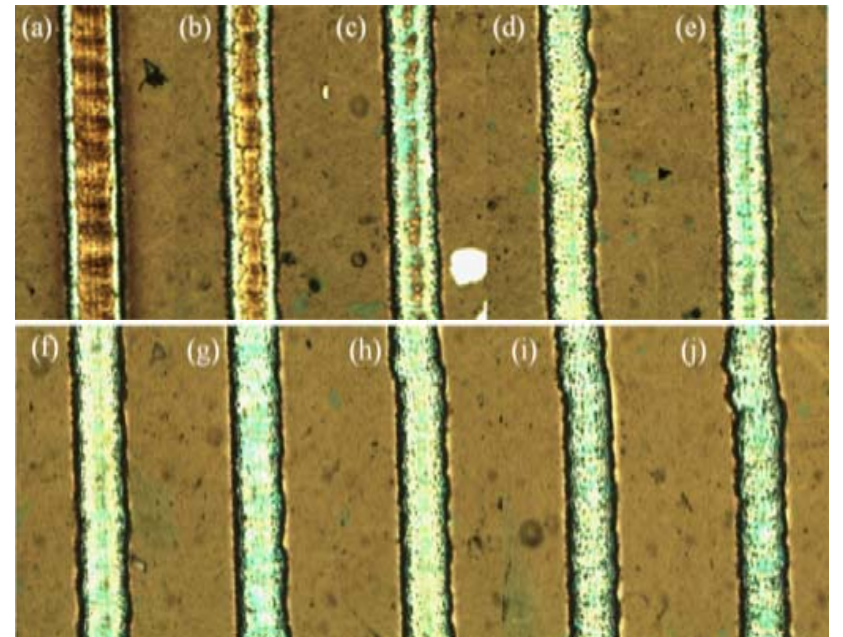

Fig. 10 Optical microscope image of the UV laser scribed $\mathrm{CIGS} / \mathrm{CdS} / \mathrm{i}-\mathrm{ZnO}$ (P2) thin-film layer at different laser frequencies. (a) $10 \mathrm{kHz}$, (b) $20 \mathrm{kHz}$, (c) $30 \mathrm{kHz}$, (d) $40 \mathrm{kHz}$, (e) $50 \mathrm{kHz}$,(f) $60 \mathrm{kHz}$, (g) $70 \mathrm{kHz}$, (h) $80 \mathrm{kHz}$, (i) $90 \mathrm{kHz}$, and (j) $100 \mathrm{kHz}$.

\subsubsection{Optimal scribing parameter results for UV laser scribing of CIGS/CdS/i-ZnO (P2) thin-film layer}

A UV laser power of $0.7 \mathrm{~W}$ and pulse frequency of 40 $\mathrm{kHz}$ produced the optimal results with a clear $\mathrm{CIGS} / \mathrm{CdS} / \mathrm{i}$ $\mathrm{ZnO}(\mathrm{P} 2)$ thin-film layer bottom. Figure 11 shows the scribing edge without the slag phenomenon; the scribing line width and depth were 69.4 and $1.19 \mu \mathrm{m}$, respectively. Figure 12 presents the results of the EDS analysis for the clear P2 thin-film layer bottom. Some debris particles and chips surrounded the scribed line edges, possibly because the P2 thin-film layer was composed of various materials whose melting points were not the same. Among them, the selenium element in the P2 thin-film layer has the lowest melting point. Therefore, during laser scribing, the selenium element melts first and flows to the bottom of the CIGS cell. The vaporized selenium material breaks cell and generates copper, indium, and gallium particles in the scribing edge. Some selenium element residuals on the bottom layer are shown in Fig. 13.

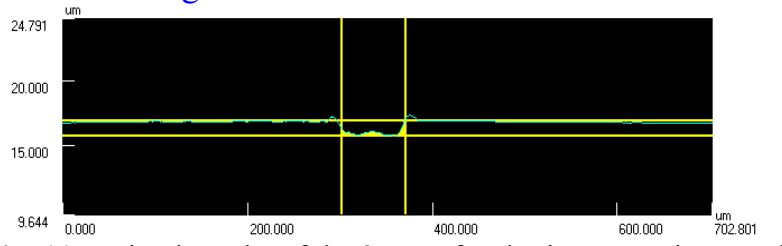

Fig. 11 Optimal results of the 3D confocal microscope image of the UV laser scribed CIGS/CdS/i-ZnO (P2) thin-film layer. (width $=69.4 \mu \mathrm{m}$, depth=1.19 $\mu \mathrm{m}$ )

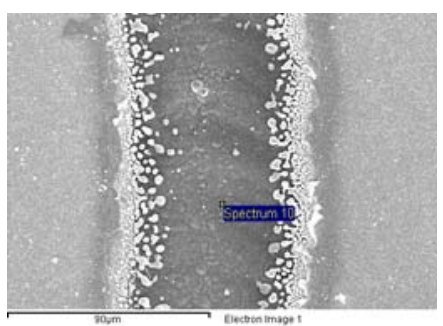

Fig. 12 SEM photography of UV laser CIGS/CdS/i-ZnO (P2) thin-film layer scribing. (laser power $=0.6 \mathrm{~W}$, pulse frequency $=60$ $\mathrm{kHz}$ )

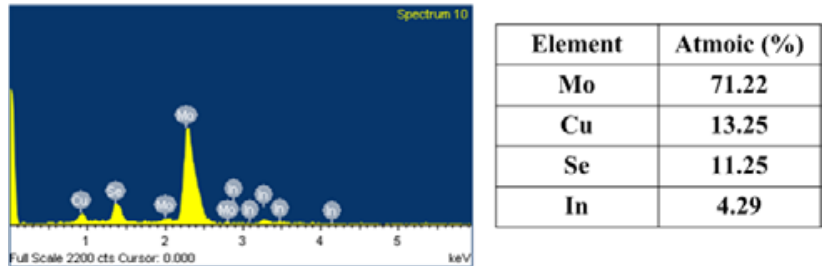

Fig. 13 EDS analysis results of UV laser scribing CIGS/CdS/i$\mathrm{ZnO}(\mathrm{P} 2)$ thin-film layer.

\subsection{UV laser isolation scribing of $\mathrm{AZO} / \mathrm{CIGS} / \mathrm{CdS} / \mathrm{i}-\mathrm{ZnO}$ (P3) thin-film layer of CIGS-based solar cells}

\subsubsection{Effect of different laser powers}

The focus position, pulse frequency, and laser beam overlapping rate were fixed at $+1 \mathrm{~mm}, 80 \mathrm{kHz}$, and $50 \%$, respectively. We then adjusted the laser power to scribe the $\mathrm{AZO} / \mathrm{CIGS} / \mathrm{CdS} / \mathrm{i}-\mathrm{ZnO}$ (P3) thin-film layer. A laser power of $0.1-0.4 \mathrm{~W}$ was ineffective in ablating the P3 thin-film layer (Fig. 14), whereas a laser power of $0.5-0.6 \mathrm{~W}$ was. At $0.7-1 \mathrm{~W}$, the crack phenomenon occurred under the bottom surface because the UV laser has higher laser intensity than does the fundamental generator $\mathrm{Nd}: \mathrm{YVO}_{4}$ laser. The scribing line widths from the UV and the fundamental generator $\mathrm{Nd}: \mathrm{YVO}_{4}$ lasers are similar. The fundamental generator $\mathrm{Nd}: \mathrm{YVO}_{4}$ laser produces smoother scribing layer bottom flatness than does the UV laser. Figure 15 shows the surface morphologies and the cross-sectional view of the UV laser scribing P3 layer at (a) $0.4 \mathrm{~W}$, (b) $0.5 \mathrm{~W}$, (c) $0.6 \mathrm{~W}$, (d) $0.7 \mathrm{~W}$, and (e) $0.8 \mathrm{~W}$. The isolation scribing line width increased with increasing laser power. Moreover, the isolation scribing line depth was controlled from 1.53 to 1.55 $\mu \mathrm{m}$ while the laser power ranged from 0.4 to $0.8 \mathrm{~W}$ (Fig. 16).

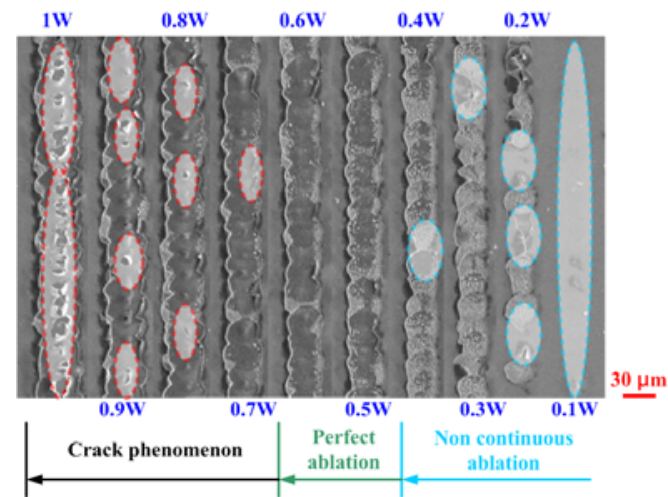

Fig. 14 SEM photography of UV laser scribing $\mathrm{AZO} / \mathrm{CIGS} / \mathrm{CdS} / \mathrm{i}-\mathrm{ZnO}$ (P3) thin-film layer at different laser powers. 

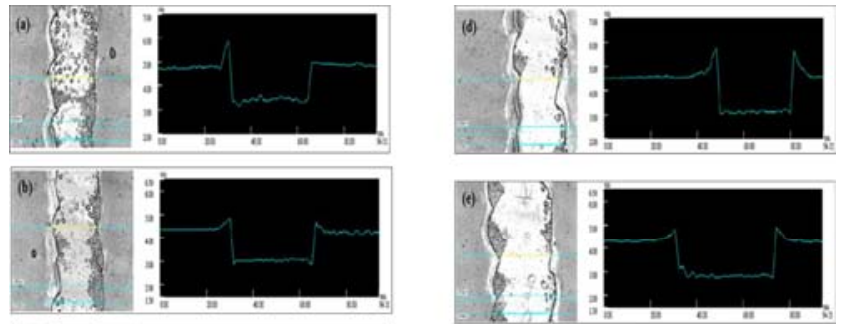

(a) $;$

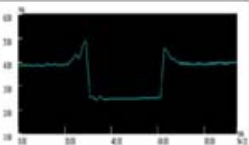

Fig. 15 3D confocal microscope images of UV laser scribing $\mathrm{AZO} / \mathrm{CIGS} / \mathrm{CdS} / \mathrm{i}-\mathrm{ZnO}(\mathrm{P} 3)$ thin-film layer at different laser powers. (a) $0.4 \mathrm{~W}$, (b) $0.5 \mathrm{~W}$, (c) $0.6 \mathrm{~W}$, (d) $0.7 \mathrm{~W}$, and (e) $0.8 \mathrm{~W}$.

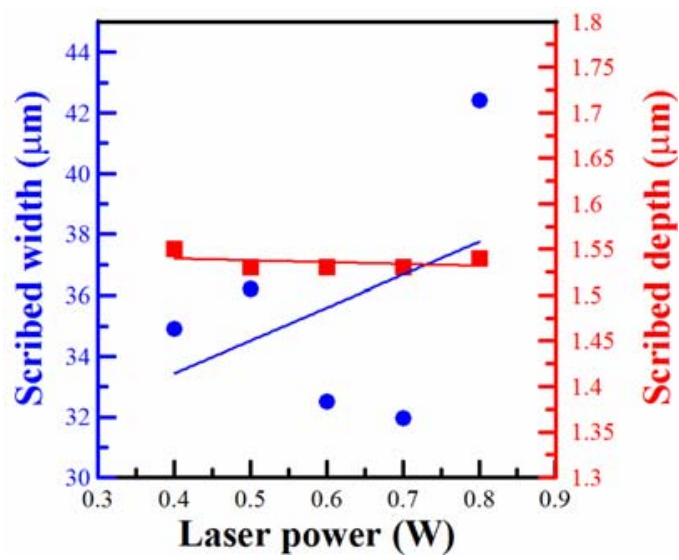

Fig. 16 Depth and width of the UV laser scribing $\mathrm{AZO} / \mathrm{CIGS} / \mathrm{CdS} / \mathrm{i}-\mathrm{ZnO}$ (P3) layer at different laser powers.

\subsubsection{Effect of different operation frequencies}

The laser power, focus point position, beam overlapping rate were fixed at $0.6 \mathrm{~W},+1 \mathrm{~mm}$, and $50 \%$, respectively. Figure 17 shows the laser scribing results of the $\mathrm{AZO} / \mathrm{CIGS} / \mathrm{CdS} / \mathrm{i}-\mathrm{ZnO}$ (P3) thin-film layer under laser pulse frequencies of $10-100 \mathrm{kHz}$. The lower the frequency, the poorer was the scribing quality. Figure 18 shows the surface morphologies and cross-sectional images of UV laser scribing of the P3 layer at (a) $40 \mathrm{kHz}$, (b) $70 \mathrm{kHz}$, (c) $80 \mathrm{kHz}$, and (d) $90 \mathrm{kHz}$. The scribing line width decreased with increasing pulse repetition frequency, and the scribing line depth increased with increasing pulse repetition frequency (Fig. 19). A comparison of the UV laser and the fundamental generator $\mathrm{Nd}: \mathrm{YVO}_{4}$ laser scribing results for the P3 layer revealed that the UV laser produced higherquality scribing than did the fundamental generator $\mathrm{Nd}: \mathrm{YVO}_{4}$ laser, because laser intensity influenced the scribing results.

\subsubsection{Optimal scribing parameter results for UV laser scribing of AZO/CIGS/CdS/i-ZnO (P3) thin-film layer \\ The UV laser system with a laser power and a pulse repetition frequency of $0.5 \mathrm{~W}$ and $80 \mathrm{kHz}$, respectively, effectively removed the $\mathrm{AZO} / \mathrm{CIGS} / \mathrm{CdS} / \mathrm{i}-\mathrm{ZnO}$ (P3) thin- film layer. We conducted 14 experiments to verify the scribing results. As shown in Fig. 20, no slag phenomenon occurred at the scribing edge. The scribed line depth and width were $1.6 \mu \mathrm{m}$ and 38-48 $\mu \mathrm{m}$, respectively (Figs. 21 and 22). Figure 23 presents the EDS analysis results for the}

laser-scribed P3 layer. The P3 layer was effectively removed and had no debris under the scribing edge.

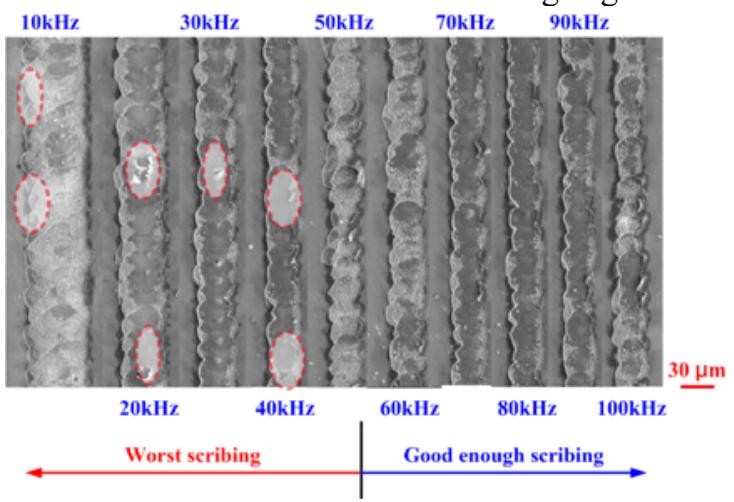

Fig. 17 UV laser scribing AZO/CIGS/CdS/i-ZnO (P3) thin-film layer at different pulse frequencies.
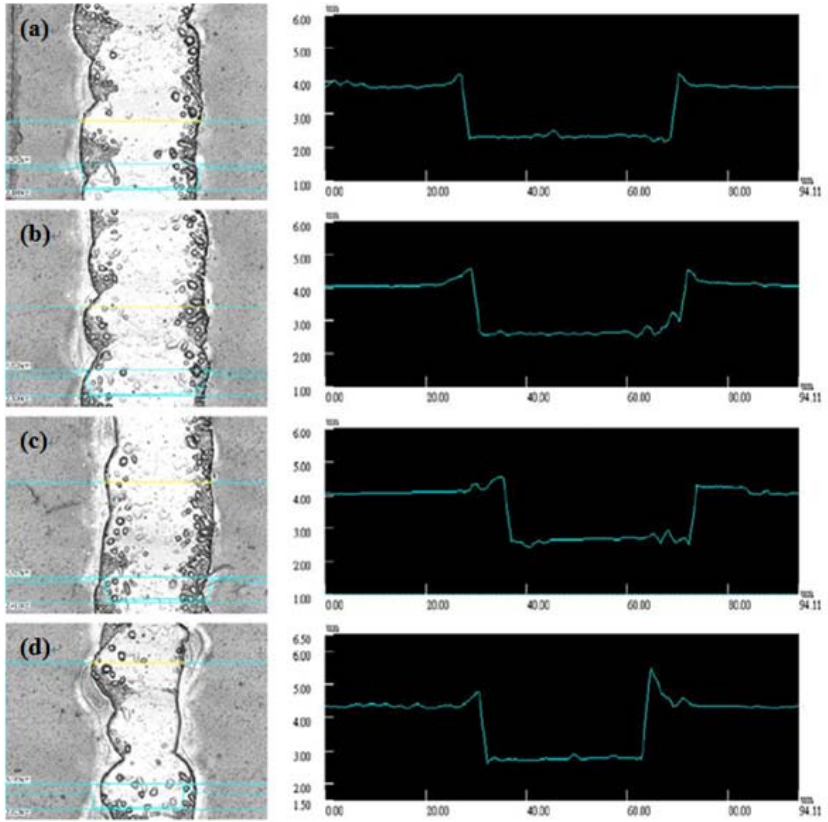

Fig. 18 3D confocal microscope images of AZO/CIGS/CdS/i-

$\mathrm{ZnO}(\mathrm{P} 3)$ thin-film layer scribed at different pulse frequencies. (a) $40 \mathrm{kHz}$, (b) $70 \mathrm{kHz}$, (c) $80 \mathrm{kHz}$, and (d) $90 \mathrm{kHz}$.

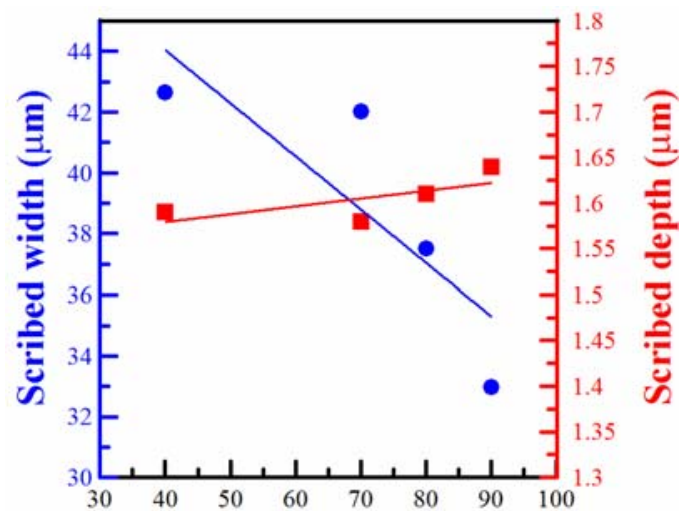

Pulse repetition frequency $(\mathrm{kHz})$

Fig. 19 Depth and width of the UV laser scribing $\mathrm{AZO} / \mathrm{CIGS} / \mathrm{CdS} / \mathrm{i}-\mathrm{ZnO}(\mathrm{P} 3)$ layer at different pulse repetition frequency. 


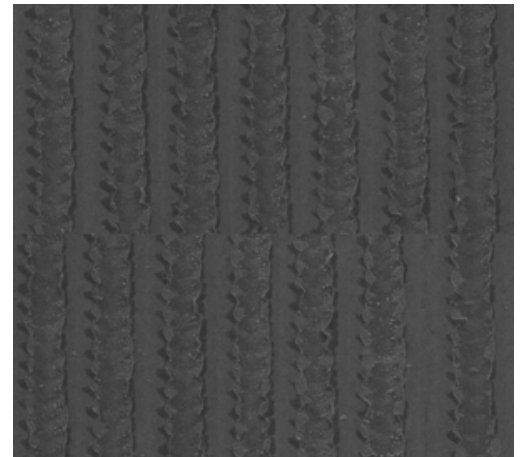

Fig. 20 UV laser scribed AZO/CIGS/CdS/i-ZnO (P3) thin-film layer verification results.

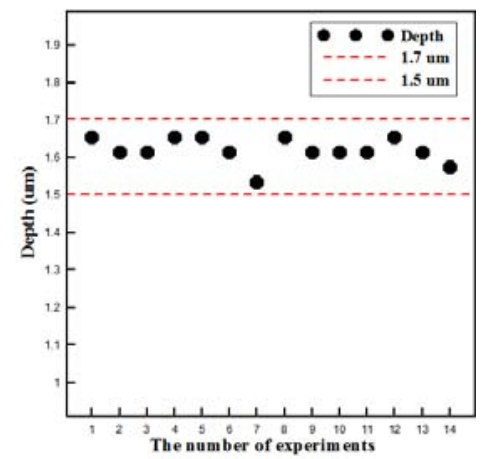

Fig. 21 Line depth of the UV laser scribed AZO/CIGS/CdS/i-ZnO (P3) thin-film layer.

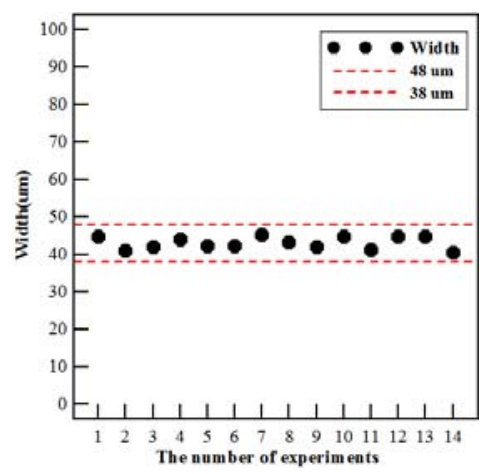

Fig. 22 Line width of the UV laser scribed AZO/CIGS/CdS/i$\mathrm{ZnO}$ (P3) thin-film layer.
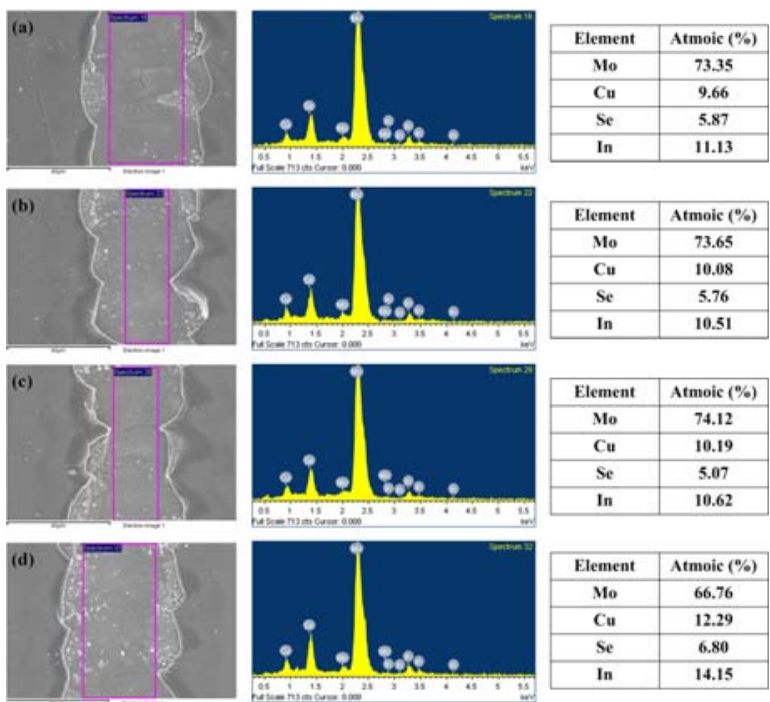

Fig. 23 EDS analysis results of UV laser scribed $\mathrm{AZO} / \mathrm{CIGS} / \mathrm{CdS} / \mathrm{i}-\mathrm{ZnO}$ (P3) thin-film layer.

\section{Conclusions}

We investigated a laser scribing process for the P1, P2, and P3 layers of CIGS-based solar cells. Current industry manufacturing processes allow only the P1 layer of the CIGS-based solar cell to be isolated and scribed using a laser, and the P2 and P3 layers still require the traditional mechanical scribing process. In the proposed process, the $\mathrm{P} 1$ layer is removed using the fundamental generator $\mathrm{Nd}: \mathrm{YVO}_{4}$ laser $(1064 \mathrm{~nm})$. The $\mathrm{P} 2$ and P3 layers are isolated and scribed using the UV laser (355 nm). Experimental results indicate that the fundamental generator $\mathrm{Nd}: \mathrm{YVO}_{4}$ laser system can effectively scribe the P1 layer at a laser power of $0.3 \mathrm{~W}$ and a pulse frequency of $80 \mathrm{kHz}$. The UV laser system is then used for scribing the P2 layer at $0.7 \mathrm{~W}$ and $40 \mathrm{kHz}$. Subsequently, the P3 layer is scribed using the same laser (UV) at $0.5 \mathrm{~W}$ and $80 \mathrm{kHz}$. In the literature, the P1, P2, and P3 layers of CIGS-based solar cells have been scribed in pico- and femtoseconds; the proposed process realized the same objective by using nanosecond laser power, which is less expensive. Moreover, nanosecond lasers provide high-quality scribing for the P2 and P3 layers of CIGS-based solar cells.

\section{References}

[1] A.D. Compaan, I. Matulionis, S. Nakade: Opt. Laser. Technol., 34, (2000) 15.

[2] P. Westin, U. Zimmermann, M. Edoff: Sol. Energy. Mater. Sol. Cells., 92, (2008) 1230.

[3] G. Račiukaitis, P. Gečys: J. Laser Micro. Nanoeng., 5, (2010) 10.

[4] M. Rekow, R. Murison, C. Dunsky, C. Dinkel, J. Pern, L. Mansfield, T. Panarello, S. Nikumb: Proc. 25th European Photovoltaic Solar Energy Conference and Exhibition / 5th World Conference on Photovoltaic Energy Conversion, (2010) p.2862.

[5] G. Heise, M. Dickmann, M. Domke, A. Heiss, T. Kuznicki, J. Palm, I. Richter, H. Vogt, H.P. Huber: Appl. Phys. A-Mater., 104, (2011) 387.

[6] P. Gečys, G. Račiukaitis, E. Miltenis, A. Braun, S. Ragnow: Phys. Procedia, 12, (2011) 141.

[7] P.O. Westin, S.C. Schmidt, M. Hüske, M. Edoff: Proc. 24th European Photovoltaic Solar Energy Conference and Exhibition, (2009) p.3087.

[8] B. Turan, S. Haas, M. Steger: Sol. Energy. Mater. Sol. Cells., 125, (2014) 78.

[9] S. Ku, B.E. Pieters, S. Haas, A. Bauer, Q. Ye, U. Rau: Sol. Energy. Mater. Sol. Cells., 108, (2013) 87.

[10]I. Matulionis, S. Nakade, A.D. Compaan: Proc. IEEE, (1997) p.491.

[11] C. Dunsky, F. Colville: Proc. SPIE. Vol. 6817, (2008) p.687129.

(Received: February 13, 2016, Accepted: June 9, 2016) 